\title{
CARACTERIZACIÓN FENOTÍPICA Y ANÁLISIS DE ADN MITOCONDRIAL DE LLAMAS DE MARCAPOMACOCHA, PERÚ
}

\author{
Phenotypic Characterization and Mitocondrial DNAAnalysis of \\ Marcapomacocha Llamas, Peru
} Lady Cano Z. ${ }^{1}$, Raúl Rosadio A. ${ }^{1,3}$, Lenin Maturrano H. ${ }^{1}$, Rosa Dávalos R..$^{1, \dagger}$,
Jane C. Wheeler ${ }^{2}$

\section{RESUMEN}

\begin{abstract}
Las llamas k'ara de Marcapomacocha, provincia de Yauli, departamento de Junín, Perú, se distinguen por presentar un alto porcentaje de animales con coloración ancestral con una semblanza muy semejante al guanaco peruano, Lama guanicoe cacsilensis. Con el objetivo de documentar estas características, aparentemente únicas de esta población, se describen medidas biométricas y análisis del ADN mitocondrial en 50 llamas (5 machos y 45 hembras de uno a más de cuatro años de edad). El patrón de coloración de las llamas muestra tonalidades desde marrón amarillento hasta rojizo oscuro, con el pecho, abdomen y la parte interna de las piernas de color casi blanco y la cabeza gris a negra con blanco alrededor de los labios, ojos y bordes de las orejas. El análisis biométrico de los 30 animales mayores a 4 años fue: altura a la cruz $123.2 \pm 12.2 \mathrm{~cm}$; altura a la grupa $119.5 \pm 8.5$ $\mathrm{cm}$, ancho de pecho $36.5 \pm 2.7 \mathrm{~cm}$, perímetro torácico $136.4 \pm 5.5 \mathrm{~cm}$, largo de orejas 19.6 \pm 2.7 , perímetro de cuello al nivel superior $42.8 \pm 2.7 \mathrm{~cm}$ y al nivel inferior $63.9 \pm 4.7 \mathrm{~cm}$, longitud corporal $118.5 \pm 5.3 \mathrm{~cm}$ y peso promedio de $152.5 \pm 12.3 \mathrm{~kg}$. Al comparar estos datos con los existentes en la literatura, se constata que las llamas de Marcapomacocha son más altas, más largas y más pesadas que las llamas k'ara de otras regiones del Perú. $\mathrm{El}$ análisis de un segmento diagnóstico del gen de citocromo $b$ (ADN mitocondrial) reveló que las 50 llamas tenían el haplotipo ancestral guanaco, indicando reducida posibilidad de hibridización con la alpaca.
\end{abstract}

Palabras clave: 1lama, Marcapomacocha, fenotipo, biometría, ADN mitocondrial

\section{Abstract}

The k'ara llama population of Marcapomacocha district, Yauli province, department of Junín, Peru is known for the preponderance of ancestral coloration in the herds. In order to document the apparently unique characteristics of these animals, phenotypic

\footnotetext{
${ }^{1}$ Unidad de Biología y Genética Molecular, Facultad de Medicina Veterinaria, Universidad Nacional Mayor de San Marcos, Lima

${ }^{2}$ CONOPA - Instituto de Investigación y Desarrollo de Camélidos Sudamericanos, Lima

${ }^{3}$ E-mail: rrosadio@gmail.com
} 
and DNA analyses were carried out on 50 llamas ( 5 male and 45 female aged 1 to $>4$ years) from the region. The coat coloration pattern of the animals was uniform, with tones varying from yellow brown to dark red brown, similar to that of the ancestral Peruvian guanaco (Lama guanicoe cacsilensis), while the chest, abdomen and inner surface of the legs are white with a grey-black head and white outlining of the lips, eyes and ears. Biometric analysis of 30 adults (4 years of age and greater) yielded the following results: withers height $123.2 \pm 12.2 \mathrm{~cm}$; rump height $119.5 \pm 8.5 \mathrm{~cm}$; chest width $36.5 \pm 2.7 \mathrm{~cm}$; chest girth $136.4 \pm 5.5 \mathrm{~cm}$; ear length $19.6 \pm 2.7$, upper and lower neck circumferences 42.8 \pm 2.7 and $63.9 \pm 4.7 \mathrm{~cm}$ respectively. Body length averaged $118.5 \pm 5.3 \mathrm{~cm}$ and body weight was $152.5 \pm 12.3 \mathrm{~kg}$. Based on a survey of the literature, the Marcapomacocha llamas are taller, longer and heavier than k'ara llamas from other regions of Peru. Analysis of a diagnostic segment of the cytochrome $b$ gene revealed that all 50 llamas had the ancestral guanaco haplotype, possibly indicating that no hybridization with alpacas has occurred.

Key words: llama, Marcapomacocha, phenotype, biometry, mitochondrial DNA

\section{INTRODUCCIÓN}

Los camélidos sudamericanos son animales de gran importancia cultural y económica para el poblador altoandino. Tienen una distribución que se extiende a lo largo de la Cordillera de los Andes, desde el sur de Colombia hasta Tierra del Fuego, aunque con mayor concentración de las especies domésticas en el altiplano peruano-boliviano (Wheeler, 1995). En estas zonas, se ubican mayormente entre los 3800 y los $5000 \mathrm{msnm}$, donde la temperatura promedio es de 6 a $8^{\circ} \mathrm{Cy}$ la precipitación pluvial anual varía desde 400 a 700 mm (Wheeler, 1995; Solís, 2000).

Los camélidos sudamericanos involucran a dos especies silvestres: el guanaco (Lama guanicoe) y la vicuña (Vicugna vicugna), y dos domésticos: la llama (Lama glama) y la alpaca (Vicugna pacos) (Kadwell et al., 2001). En el 2005, se reportó para el Perú una población de tres millones de alpacas, un millón de llamas, alrededor de 125 mil vicuñas y 5 mil guanacos (FAO, 2005). Es así que en el Perú se encuentra el 54\% (188 372) de la población de vicuñas de América del Sur (Lichtenstein et al., 2010) y, escasamente, cuatro mil ejemplares de guanacos andinos (L.g. cacsilensis) comparados con los 600000 de la subespecie patagónica L.g. guanicoe (Baldi et al., 2010). La población actual de L.g. cacselinsis, en el Perú, tiene una tendencia decreciente y se estima que sería menos de tres mil debido a las altas tasas de caza deportiva, que pueden llevar a esta especie a la extinción en 50 años (Wheeler et al., 2006).

La crianza de camélidos sudamericanos, desde época prehispánica, ha sido de vital importancia para los pobladores altoandinos (Wheeler, 1995), y particularmente importante para alrededor de 2.9 millones de campesinos ( $12 \%$ de la población nacional) de 1000 comunidades en los departamentos de Apurímac, Arequipa, Ayacucho, Cusco, Huancavelica, Junín y Puno, que se dedican a la esquila de vicuñas y la crianza de alpacas y llamas, para aprovechar la fibra, carne y transportar productos agrícolas (FAO, 2005). Esta crianza, generalmente, se realiza en las zonas de gran altura, donde la agricultura y la ganadería basada en especies introducidas son poco viables (Franco et al., 1998; Solís, 2000).

La acelerada desaparición de razas de animales domésticos en el mundo ha llevado a la FAO a emitir un mandato destinado a preservar y conservar las razas domésticas (FAO, 2009). Este mandato, sin embargo, es poco conocido y pobremente implementado en muchos países firmantes del convenio de 1992. En el Perú, se describe la existencia de dos variedades de llamas, una "lanuda" (chaku) y otra desprovista de fibra (k'ara) 
(Sumar, 1993), pero se presume la existencia de pequeñas poblaciones (ecotipos) con características fenotípicas muy particulares que son desconocidas o escasamente documentadas (Wheeler, 1994). Este trabajo describe las principales características fenotipicas y el análisis de ADN mitocondrial realizado en 50 llamas k'aras criadas en Marcapomacocha, Junín, donde más del 90\% de los animales posee una uniformidad fenotípica caracterizada por conservar la coloración de su ancestro, el guanaco (Lama guanicoe cacsilensis) (Franklin, 1983).

\section{Materiales y MÉTOdos}

\section{Lugar de Estudio y Animales}

El estudio se realizó en el distrito de Marcapomacocha, provincia de Yauli, departamento de Junín, (76 $18^{\circ}$ " W, 11 20 " S), Perú, localizado a una altitud de $4413 \mathrm{msnm}$. Marcapomacocha es un pueblo a orillas de la laguna del mismo nombre, en la desembocadura del río Mantaro, con vegetación de puna y algunas áreas de terrenos pantanosos. En esta localidad se crían alrededor de 400 llamas con características muy particulares, mostrando principalmente una coloración fenotípica uniforme que se asemeja a la del guanaco. Los animales se crían en forma extensiva y se alimentan de pastos naturales sin recibir suplementación aditiva.

El muestreo se realizó en los meses de agosto y setiembre de 2005 en dos de los cuatro únicos productores que mantenían predominantemente llamas k'ara de coloración semejante al guanaco (Franklin, 1983). Se seleccionó llamas mayores de un año que cumplían con este tipo de coloración, obteniéndose 50 llamas del tipo k'ara (5 machos y 45 hembras) de edad diversa ( 9 de un año, 6 de dos, 1 de tres, 4 de cuatro y los 30 restantes mayores de 4 años). Debido al escaso número de animales de 1-3 años, sólo se consideraron los animales hembras mayores de 4 años para los análisis biométricos comparativos, en tanto que se incluyeron los
50 animales, sin importar sexo o edad para el estudio de ADN mitocondrial.

\section{Metodología}

Los animales tenían identificación individual con aretes metálicos. Se colectó muestras de sangre y se les tomó las medidas corporales en los corrales para facilitar su sujeción. Se anotó el sexo y se estimó la edad usando la técnica del boqueo utilizada en alpacas (Fernández Baca, 1962; Wheeler, 1982).

\section{Descripción fenotípica}

Las características fenotípicas se basaron en la descripción del tipo y distribución corporal de la coloración. Todos los animales fueron fotografiados.

\section{Medidas biométricas}

Se obtuvieron en un sólo momento y por la misma persona. El animal fue inmovilizado y las medidas corporales fueron tomadas con la mayor exactitud posible, utilizando una cinta métrica zootécnica, siguiendo los patrones de medidas que se indican en la Fig. 1.

La altura a la cruz se midió entre las apófisis espinosas de las vertebras torácicas a la superficie del piso y la altura a la grupa entre la espina sacra del primer segmento sacro hasta la superficie del piso. El ancho del pecho fue la medida entre las articulaciones escápulo humerales. El perímetro torácico se midió tomando como base la quinta vertebra torácica y el esternón por detrás de la línea del codo. El largo del cuello desde la articulación atlanto-occipital hasta la última vértebra cervical, determinándose, además, el perímetro superior (alrededor de la primera cervical) y el perímetro inferior (alrededor de la séptima cervical). El largo de la cara desde la base de la oreja hasta el fin del hocico y la longitud de la oreja desde la base hasta la punta de la misma. Se midió, además, la longitud de la cola (primera vertebra coxígea hasta el final de la cola) y la longitud del cuerpo (fin del pecho hasta la punta de los isquiones). 
Todas las medidas morfológicas fueron expresadas en centímetros siguiendo lo descrito por García y Franco (2006), Llacsa et al. (2007) y Zea et al. (2007).

El peso vivo fue estimado en base a las medidas del perímetro torácico y perímetro superior del cuello, utilizando la ecuación descrita por García y Franco (2006): $\mathrm{PV}=-160.68+1.81 \mathrm{PT}+1.55 \mathrm{PSC}$, en donde PV es el peso vivo estimado en kilogramos, $\mathrm{PT}$ es el perímetro torácico y PSC es el perímetro superior del cuello, ambos expresados en centímetros.
Muestras de sangre y extracción de ADN

Se colectó $2 \mathrm{ml}$ de sangre por punción yugular de cada animal, utilizando tubos al vacío (Vacutainer ${ }^{\circledR}$ ) con EDTA. Las muestras fueron conservadas a $-20{ }^{\circ} \mathrm{C}$. La extracción y análisis de ADN se realizó en la Unidad de Genética y Virología Molecular de la Facultad de Medicina Veterinaria, Universidad Nacional Mayor de San Marcos. La extracción de ADN fue realizado según lo descrito por Sambrook et al. (1989), utilizando la solución tampón QLB (Queen's Lysis Buffer) y Proteinasa K, incubándolos por 24 horas
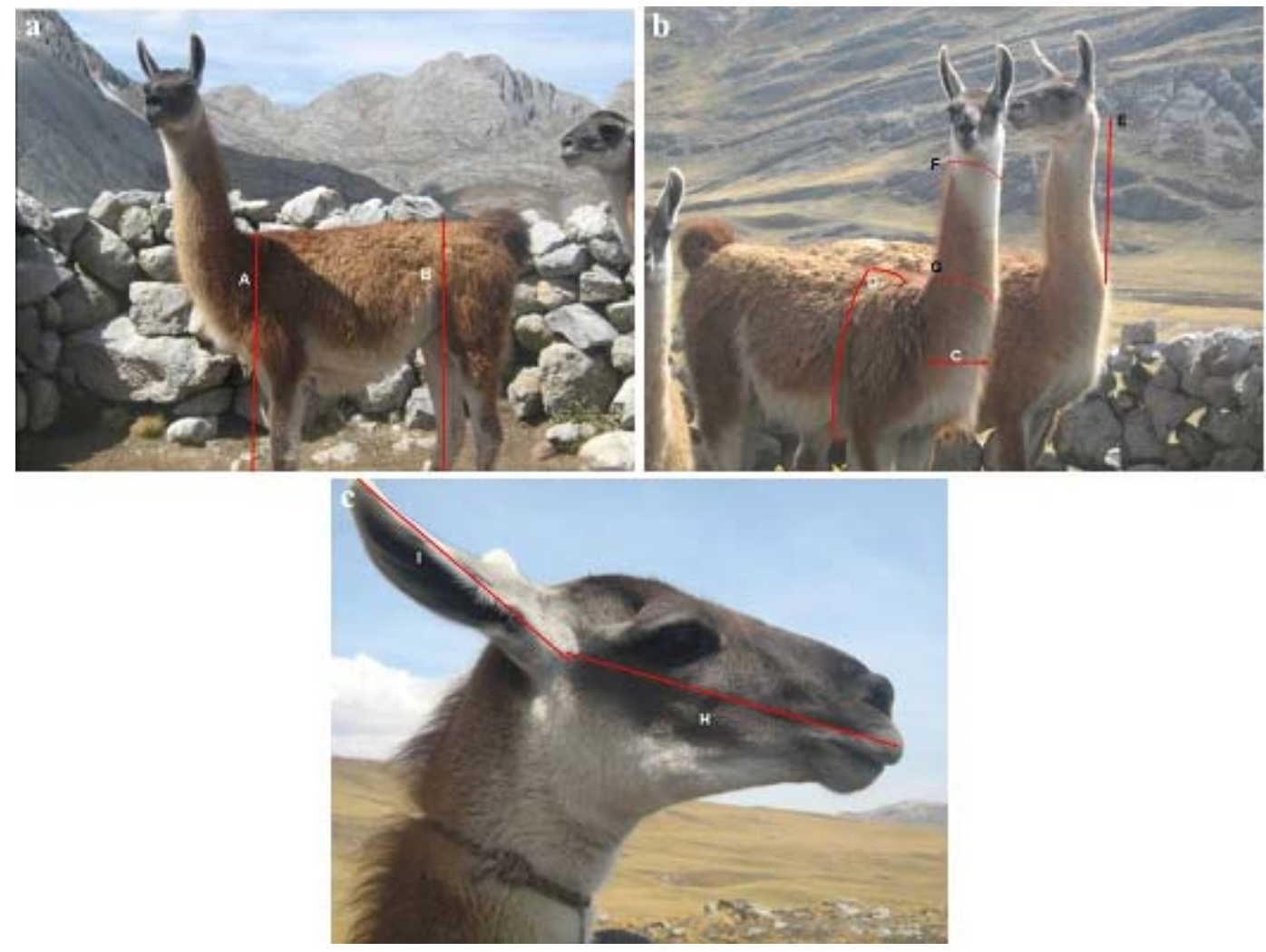

Figura 1. Fotografías de llamas que ilustran el esquema empleado para la obtención de las medidas biométricas. Foto A: (a) Altura a la cruz; (b) Altura a la grupa. Foto B: (c) Ancho del pecho; (d) Perímetro torácico; (e) Largo del cuello; (f) Perímetro superior del cuello; (g) Perímetro inferior del cuello. Foto C: (h) Largo de la cara; (i) Largo de la oreja 
para la digestión celular. Para la extracción del ácido nucleico propiamente dicho, se utilizó el método Fenol Cloroformo Alcohol Isoamílico para remover las proteínas y finalmente precipitar el ADN con etanol al 100\% (Sambrook et al., 1989).

\section{Análisis de ADN mitocondrial}

Para el análisis del ADN mitocondrial se evaluó el gen citocromo B (cyt B) mediante PCR. La prueba utilizó $2.0 \mu 1$ de ADN con concentraciones que van desde 25 a 50 $\mathrm{ng} / \mu \mathrm{l}$ en un microtubo conteniendo la preparación Mix 1X: Buffer de 10X $(150 \mu 1), 1.5$ $\mathrm{mM} \mathrm{MgCl}(90 \mu \mathrm{l}), 0.25 \mathrm{mM}$ dNTPs $(187.5$ $\mu 1)$ y $\mathrm{H}_{2} \mathrm{O}$ PCR $(1042.5 \mu 1)$. Posteriormente, se adicionó $0.25 \mu \mathrm{ldel}$ cebador $\mathrm{H}(40 \mathrm{pmol} /$ $\mu 1), 0.25 \mu$ del cebador L (40 pmol $7 \mu 1), 0.1$ $\mu 1$ de Taq DNA pol ( $5 \mathrm{U} / \mu 1$ ) obteniéndose un volumen final de $15.0 \mu 1$. Los productos de PCR fueron obtenidos utilizando un termociclador modelo 4200 GeneAmp ${ }^{\circledR}$ (Perkin Elmer). Los productos de PCR (10 $\mu 1)$ del gen cyt B fueron posteriormente sometidos a la digestión enzimática utilizando la enzima de restricción Mbo I $(0.2 \mu \mathrm{l})$, siguien- do el procedimiento establecido en el laboratorio en busca de fragmentos de 158 y 50 pares de bases típicos de animales con haplotipo guanaco (Stanley et al., 1994), y ser visualizados en geles de agarosa al $3 \%$ a $70 \mathrm{~V}$ y teñido con bromuro de etidio $(2 \mu \mathrm{g} /$ $\mathrm{ml}$ ) por 20 minutos.

\section{Análisis Estadístico}

Se calculó las medias y desviaciones estándar de las medidas biométricas. Sólo los valores de llamas mayores de 4 años $(n=30)$ fueron usados para la comparación con valores obtenidos en otros estudios. Así, las variables biométricas fueron comparadas con los resultados encontrados en llamas del distrito de Huayllay, Pasco (Álvarez, 2001), distrito de Nuñoa, Puno (García y Franco, 2006), distrito de Santa Rosa de Juli, Puno (Paca, 1977), del departamento de Cusco (Estrada, 1983) y del Centro Experimental La Raya, Puno (Maquera Llano, 1991). Además, para determinar la semejanza de la población de llamas de Marcapomacocha con sus antecesores, los guanacos, se compararon las variables biométricas con los resultados encon-
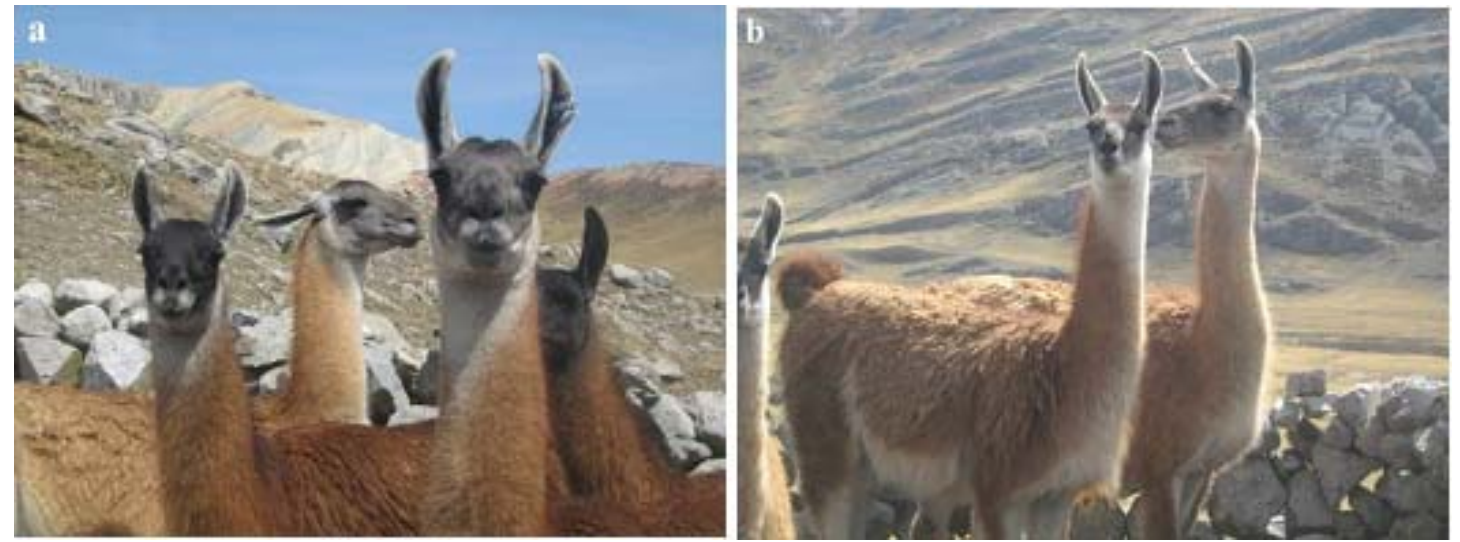

Figura 2. Llamas de Marcapomacocha. (a) Se observa las características de la cara y orejas; (b) Pareja de llamas mostrando tonalidades uniforme de color marrón con franja blanca en la parte ventral 

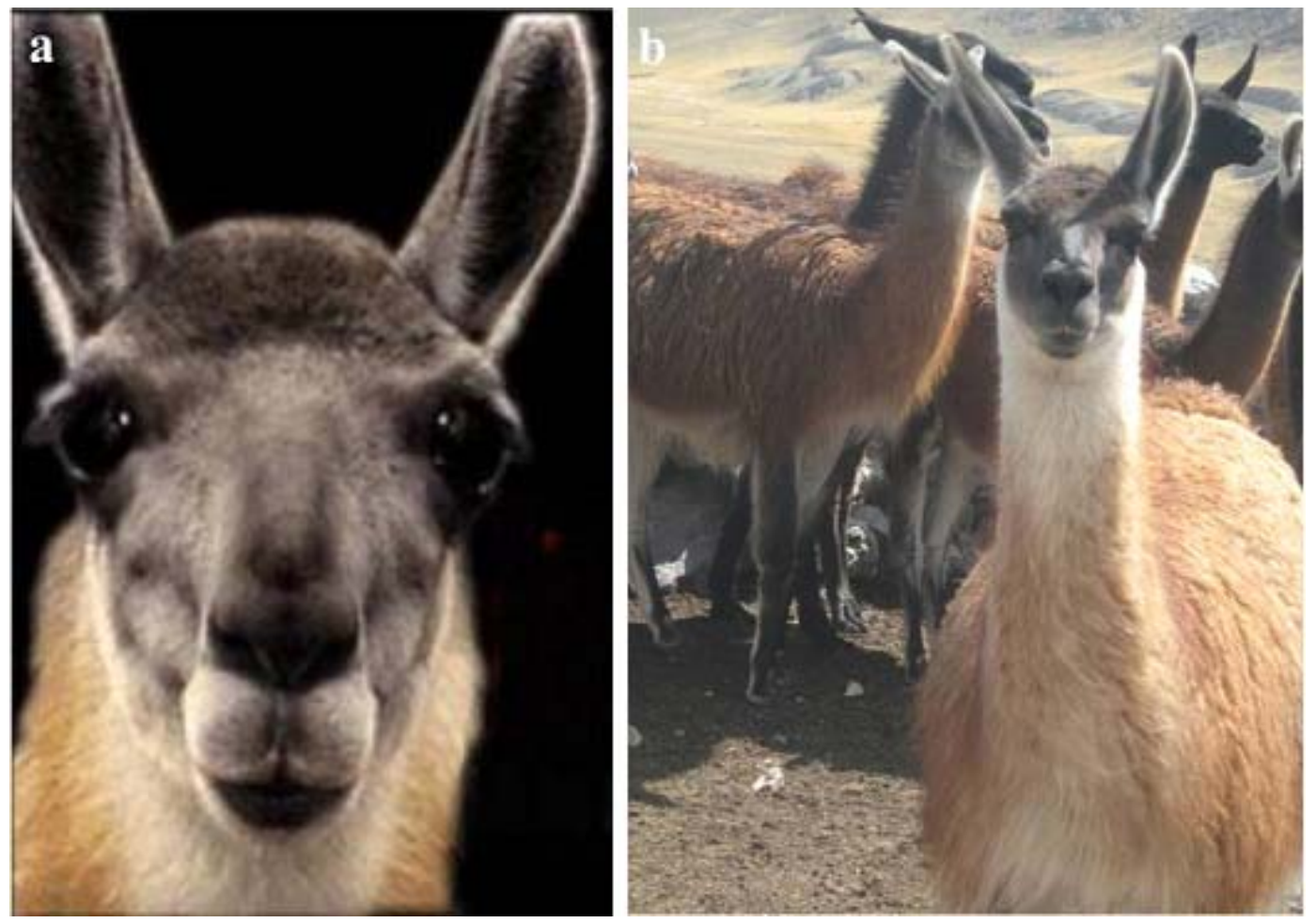

Figura 3. Fotografías de camélidos sudamericanos. (a) Cara de un guanaco andino peruano (Lama guanicoe cacsilensis); (b) Grupo de llamas (Lama glama) de Marcapomacocha

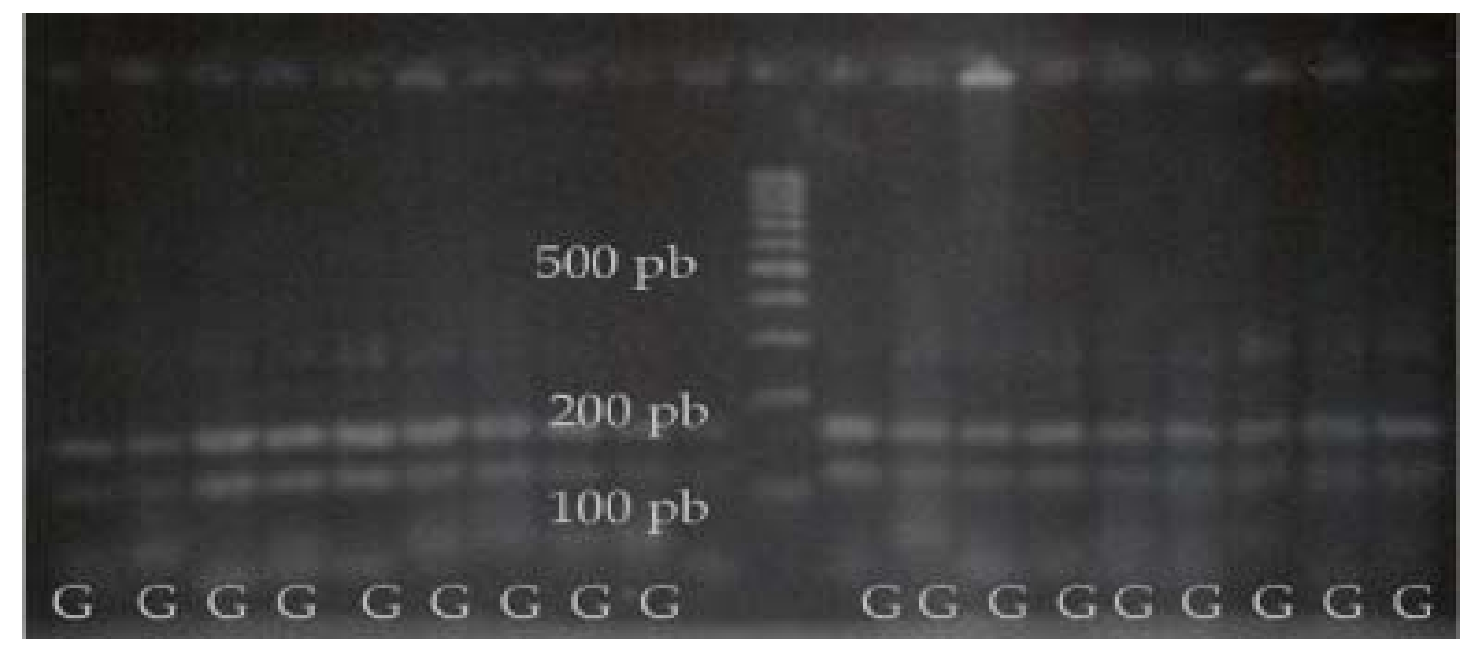

Figura 4. Análisis mitocondrial en muestras de sangre de llamas de Marcapomacocha. Nótese la presencia de dos bandas digeridas por la enzima de restricción y característica del haplotipo guanaco $(\mathrm{G})$ 
Cuadro 1. Medidas biométricas en llamas de Marcapomacocha, según edad

\begin{tabular}{|c|c|c|c|c|c|}
\hline Medida biométrica & $\begin{array}{l}1 \text { año } \\
(\mathrm{n}=9)\end{array}$ & $\begin{array}{c}2 \text { años } \\
(\mathrm{n}=6)\end{array}$ & $\begin{array}{c}3 \text { años } \\
(n=1)\end{array}$ & $\begin{array}{c}4 \text { añ os } \\
(\mathrm{n}=4)\end{array}$ & $\begin{array}{c}>4 \text { años } \\
(\mathrm{n}=30)\end{array}$ \\
\hline \multicolumn{6}{|l|}{ De talla } \\
\hline $\begin{array}{l}\text { Altura a la cruz } \\
(\mathrm{cm})\end{array}$ & $110.7 \pm 3.6$ & $115.1 \pm 3.8$ & 122.5 & $119.0 \pm 3.4$ & $123.2 \pm 12.2$ \\
\hline $\begin{array}{l}\text { Altura a la grupa } \\
(\mathrm{cm})\end{array}$ & $113.7 \pm 6.4$ & $118.1 \pm 2.5$ & 127.5 & $126.9 \pm 3.0$ & $119.5 \pm 8.5$ \\
\hline \multicolumn{6}{|l|}{ Del tórax } \\
\hline $\begin{array}{l}\text { Ancho del pecho } \\
(\mathrm{cm})\end{array}$ & $33.8 \pm 2.5$ & $36.1 \pm 5.2$ & 34.8 & $36.6 \pm 3.9$ & $36.5 \pm 2.7$ \\
\hline $\begin{array}{l}\text { Períme tro torácico } \\
(\mathrm{cm})\end{array}$ & $121.6 \pm 5.4$ & $130.0 \pm 7.7$ & 136.5 & $137.8 \pm 3.7$ & $136.4 \pm 5.5$ \\
\hline \multicolumn{6}{|l|}{ Del cuello } \\
\hline $\begin{array}{l}\text { Largo del cuello } \\
(\mathrm{cm})\end{array}$ & $62.2 \pm 4.5$ & $70.7 \pm 4.4$ & 72.3 & $67.9 \pm 4.6$ & $70.6 \pm 4.8$ \\
\hline $\begin{array}{l}\text { Perímetro sup erior } \\
\text { del cuello }(\mathrm{cm})\end{array}$ & $40.7 \pm 6.7$ & $40.7 \pm 3.7$ & 40.7 & $43.8 \pm 3.3$ & $42.8 \pm 2.7$ \\
\hline $\begin{array}{l}\text { Perímetro inferior } \\
\text { del cuello }(\mathrm{cm})\end{array}$ & $62.1 \pm 7.6$ & $63.5 \pm 6.7$ & 69.5 & $64.3 \pm 3.0$ & $63.9 \pm 4.7$ \\
\hline \multicolumn{6}{|l|}{ De la cara } \\
\hline $\begin{array}{l}\text { Largo de la cara } \\
(\mathrm{cm})\end{array}$ & $23.9 \pm 3.8$ & $23.5 \pm 3.6$ & 27.0 & $28.1 \pm 3.9$ & $26.2 \pm 4.4$ \\
\hline $\begin{array}{l}\text { Longitud de oreja } \\
(\mathrm{cm})\end{array}$ & $19.6 \pm 4.5$ & $20.1 \pm 4.5$ & 19.6 & $19.4 \pm 2.5$ & $19.6 \pm 2.7$ \\
\hline \multicolumn{6}{|l|}{ Otras medidas } \\
\hline $\begin{array}{l}\text { Longitud de la cola } \\
(\mathrm{cm})\end{array}$ & $25.0 \pm 4.8$ & $33.0 \pm 1.8$ & 26.5 & $32.4 \pm 4.1$ & $29.7 \pm 4.4$ \\
\hline $\begin{array}{l}\text { Longitud del cuerpo } \\
(\mathrm{cm})\end{array}$ & $101.3 \pm 8.9$ & $117.3 \pm 4.5$ & 112.0 & $119.9 \pm 3.8$ & $118.5 \pm 5.3$ \\
\hline $\begin{array}{l}\text { Peso vivo estimado } \\
\text { (kg) }\end{array}$ & $122.6 \pm 14.0$ & $137.7 \pm 18.6$ & 149.5 & $156.6 \pm 5.3$ & $152.5 \pm 12.3$ \\
\hline
\end{tabular}

trados en guanacos peruanos (Wheeler, 1995) y de la reserva del Ministerio de Agricultura y Ganadería de Río Negro, Bolivia (Larrieu et al., 1979).

\section{RESULTADOS}

La mayoría de los animales muestreados tenían colores casi uniformes mostrando algunas diferencias en la intensidad del pelaje corporal. Las llamas de Marcapomacocha tienen el cuerpo cubierto por un manto de tonalidades marrones (amarillento a rojizo oscuro), muy semejante al color del vellón del guanaco peruano (Figs. 2 y 3 ), pero mostrando una franja blanca que recubre el pecho, abdomen y la parte interna de las piernas. La cabeza evidencia tonalidades que varían de gris a negra con coloraciones blanquecinas alrededor de los labios, ojos y bordes de las orejas (Fig. 2) en una forma mucho más evidente que en los guanacos.

Las mediciones biométricas de las 50 1lamas se muestran en el Cuadro 1. Los ani- 
males tienen orejas largas en forma de cartucho con presencia de fibras cortas (Fig. 3). El peso vivo estimado varió entre $122.6 \pm 14.0$ $\mathrm{kg}$ en las llamas de un año hasta $152.5 \pm 12.3$ $\mathrm{kg}$ en animales mayores de cuatro años de edad.

Se logró la extracción y amplificación del gen cyt B, mediante PCR, de todas las muestras. Al realizar el análisis de restricción, todas las muestras mostraron las dos bandas de 158 y $50 \mathrm{pb}$, característicos del haplotipo guanaco (Fig. 4).

\section{Discusión}

Más del 90\% de las 1lamas de Marcapomacocha se caracterizan por tener un fenotipo muy semejante al de su ancestro Lama guanicoe cacsilensis, el guanaco peruano (coloración ancestral). La concentración de animales con este fenotipo en esta localidad es excepcional, pues es extremadamente rara en el resto de la población nacional y andina.

El fenotipo típico de las 50 llamas, en general, es muy semejante (Figs. 1, 2 y 3) pero, por ser animales domésticos, no son tan uniformes como los silvestres (Franklin, 1983; Wheeler, 1995). En estos animales, a pesar de que predomina el patrón del pelaje con tonos rojizo oscuro a amarrillo arcilloso, cabeza gris a negra y blanco en el pecho, vientre, sector interno de las piernas y alrededor de los labios, ojos y bordes de las orejas, se puede observar variaciones en la coloración de la cara con aumento de blanco o negro y manchas, así como aumento en el área del cuerpo cubierta de blanco. Sin embargo, aún en los animales más claros, se puede distinguir el patrón de coloración ancestral (Franklin, 1983; Wheeler, 1995).

Estas diferencias en coloración son un tanto diferente al guanaco, donde los individuos tienen una coloración semejante del pelaje, variando de marrón oscuro rojizo a un marrón más claro con tonos amarrillentos arcillosos (Wheeler, 1995). El pecho, vientre y sector interno de las piernas son de un color blanco más o menos puro; y la cabeza entre gris y negro con blanco en los alrededores de los labios, ojos y bordes de las orejas (Wheeler, 1995).

Al comparar las medidas biométricas de las llamas de Marcapomacocha (mayores de cuatro años) con las de otras poblaciones de llamas, se observa que estas son de mayor tamaño y poseen una mayor masa corporal que el resto de animales presentes en los Andes centrales y del sur del país. Las 30 llamas mayores de 4 años tenían $123.2 \pm 12.2 \mathrm{~cm}$ de altura a la cruz y $119.5 \pm 8.5 \mathrm{~cm}$ de altura a la grupa (Cuadro 1). Estas llamas eran mucho más grandes que aquellas descritas por Álvarez (2001) y García y Franco (2006). Asimismo, exceden en tamaño a las llamas de Cusco (Estrada, 1983) y de Santa Rosa de Juli, Puno (Paca, 1977). Las llamas de Marcapomacocha tienen, igualmente, un mayor perímetro de cuello a nivel superior $(42.8 \pm 2.7 \mathrm{~cm})$ y nivel inferior $(63.9 \pm 4.7$ $\mathrm{cm})$ que sus similares de Cerro de Pasco (33.6 y $41.4 \mathrm{~cm}$, respectivamente) (Álvarez, 2001) y de Puno (32.0 y $47.1 \mathrm{~cm}$, respectivamente) (García y Franco, 2006).

Las llamas estudiadas también son más largas $(118.5 \pm 5.3 \mathrm{~cm})$ comparadas con otras poblaciones de 1lamas (Álvarez, 2001; Pumayalla et al., 1985). En relación al largo de las orejas, las llamas de Marcapomacocha registraron $19.6 \pm 2.7 \mathrm{~cm}$; medidas un tanto distintas de las registradas en animales procedentes de Santa Rosa de Juli, Puno, con medidas promedios de $19 \mathrm{~cm}$ en animales de 5 años de edad de ambos sexos (Paca, 1977).

En cuanto al peso vivo, las llamas de Marcapomacocha se estimaron en $152.5 \pm$ $12.3 \mathrm{~kg}$, bastante más pesadas que los animales procedentes de Cerro de Pasco descritos por Álvarez (2001) (104.6 kg), y en Puno descritas por García y Franco (2006) (86.6 kg), Bustinza y Saucapuca (1987) (83$93 \mathrm{~kg}$ ), Maquera (1991) (90.7 kg) y, largamente, a los pesos de 68.3 y $76.7 \mathrm{~kg}$ para 
hembras y machos, respectivamente, reportados por Pumayalla et al. (1985). Similarmente, estos animales son más pesadas que las k' aras $(90.7 \mathrm{~kg})$ y t'ampullis (83.0 $\mathrm{kg}$ ) adultos bolivianos (Cardozo, 1995). Aunque las medidas biométricas corresponden a un pequeño grupo de llamas, es posible notar diferencias que podrían estar relacionadas a su alimentación, manejo o factores genéticos, todos ellos relacionados a un ecotipo distinto.

Los parámetros encontrados en las 1lamas de Marcapomacocha no pueden, desgraciadamente, contrastarse con similares datos de sus ancestros andinos debido a la casi inexistencia de información para el guanaco andino (Lama guanicoe cacsilensis); sin embargo, son tan altos como el guanaco adulto patagónico (L.g. guanicoe de la Tierra del Fuego y la Patagonia), quienes presentan una altura a la cruz de 110 a $120 \mathrm{~cm}$ (Cabrera y Yepes, 1960; Franklin, 1982). El largo del cuerpo de estos animales tampoco pudo ser comparados con los valores reportados en animales silvestres, ya que dichos estudios emplearon bases anatómicas diferentes (punta de la nariz a la base de la cola), indicando valores de 167 a $210 \mathrm{~cm}$ para L. g. guanicoe (MacDonagh, 1949; Cabrera y Yepes, 1960) y de 90 a $100 \mathrm{~cm}$ para L. $g$. cacsilensis andino (Solís, 2000).

El peso promedio de las 1lamas de Marcapomacocha fue mayor que los promedios descritos para animales adultos de $L . g$. guanicoe (120-130 kg) y de L.g. cacsilensis (96 kg) (Solís, 2000; Zúñiga, 2004).

Las características genéticas de estos animales no han podido ser analizadas detalladamente; sin embargo, el análisis del gendel citocromo $b$ del ADN mitocondrial muestra que todos los animales poseen el haplotipo del ADNmt, similar al del ancestro evolutivo: el guanaco. Esta perfecta proporción (100\%) es superior a lo esperado para llamas andinas (solo $40 \%$ con haplotipo guanaco) y distinta a lo encontrado en un estudio transversal de la región andina (Stanley et al., 1994), y sobre todo para llamas peruanas, donde se estima que 10 a $15 \%$ tienen el haplotipo guanaco (Wheeler et al., 1995).
Las grandes diferencias en los datos biométricos sugieren que las llamas de Marcapomacocha deben pertenecer a un ecotipo de llamas distinto a los reportados previamente en otras partes del país, lo cual amerita estudios confirmatorios posteriores. Los resultados evidencian, además, que estos animales podrían haberse mantenido evolutivamente aislados o que el esquema de apareamiento ha utilizado únicamente a hembras con haplotipo guanaco (llamas). Para corroborar la homogenicidad de la descendencia maternal en estos animales será necesario extender el análisis a otros marcadores a nivel de ADN nuclear (microsatélites) y determinar la supuesta no hibridización y, a su vez, medir la variabilidad genética de esta población aparentemente ancestral de llama de los Andes centrales del Perú.

\section{Conclusiones}

- El estudio documenta algunas características físicas que separan las llamas k'aras de Marcapomacocha de otras poblaciones de llamas en el Perú y los Andes.

- Son animales que mantienen, homogéneamente, el color ancestral de la especie silvestre y muestran ciertos parámetros como el tamaño y contextura mayor a otras llamas criadas en el Perú y Bolivia.

- La descripción de este tipo de llama indica la posible existencia de una desconocida diversidad genética de camélidos domésticos en el país que necesita ser estudiada.

\section{Literatura Citada}

1. Álvarez G. 2001. Morfometría y sus relaciones en llamas Ccara de la empresa comunal Los Andes Palcan-Pasco. Tesis Ing Zootecnista. Huancayo: Facultad de Zootecnia, Univ Nacional del Centro del Perú. 82 p. 
2. Baldi B, Lichtenstein G González B, Funes M, Cuellar E, Villalba L, et al. 2010. Lama guanicoe. En: IUCN Red List of Threatened Species, Version 2010.2. [Internet]. Available in: www.iucnredlist.org

3. Bustinza V, Saucapuca V. 1987. La situación de la llama en Puno. Allpaka 1: 1-15.

4. Cabrera A, Yepes J. 1960. Mamíferos sudamericanos. $2^{\circ}$ ed. Buenos Aires: Ediar. $187 \mathrm{p}$.

5. Cardozo A. 1995. Tipificación de las llamas Karas y Tampullis. En: Genin D, Picht HJ, Lizarazu, Rodríguez T (eds). Waira Pampa, un sistema pastoril camélidos-ovinos del Altiplano árido boliviano. La Paz: ORSTOM, CONPAC, IBTA. p 65-72.

6. Estrada C. 1983. Zoometría y algunas correlaciones en llamas. Tesis de Ingeniero Zootecnista. Cusco: Facultad de Zootecnia, Univ San Antonio Abad. 81 p.

7. FAO. 2005. Situación actual de los camélidos sudamericanos en el Perú. Proyecto de cooperación técnica en apoyo a la crianza y aprovechamiento de los camélidos sudamericanos en la Región Andina TCP/RLA/2914. 62 p.

8. FAO. 2009. Livestock keepers guardians of biodiversity. FAO Animal Production and Health Paper No. 167, Rome. 48 p.

9. Fernández-Baca S. 1962. Algunos aspectos del desarrollo dentario de la alpaca (Lama pacos). Rev Fac Med Vet 1617: 88-103.

10. Franco E, García W, Pezo D. 1998. Manual de crianza de llamas. Pub Téc FMV Perú N. ${ }^{\circ}$ 33. Lima: UNMSM. 42 p.

11. Franklin WM. 1982. Contrasting socioecologies of South America's wild camelids: the vicuña and the guanaco. In: Eisenberg JF, Kleinman DH (eds). Advances in the study of mammalian behaviour. Special Publication 7. Kansas, USA: American Society of Mammologists. p 573-629.
12. García W, Franco E. 2006. Estudio de las principales medidas biométricas y desarrollo de modelos de predicción de peso vivo en llamas. IV Congreso Mundial sobre Camélidos. Catamarca, Argentina.

13. Kadwell M, Fernández M, Stanley HF, Baldi R, Wheeler JC, Rosadio R, Bruford MW. 2001. Genetic analysis reveals the wild ancestors of the llama and the alpaca. P Roy Soc Lond B Bio 268: 2575-2584.

14. Larrieu E, Bigatti R, Oporto N. 1979. Somatometría en guanacos de Río Negro. XXXII Congreso Internacional de Camélidos Sudamericanos. Río Negro, Argentina.

15. Lichtenstein G Baldi R, Villalba L, Hoces D, Baigún R, Laker J. 2010. Vicugna vicugna. En: IUCN - Red List of Threatened Species, Version 2010.2. [Internet]. Available in: www.iucnredlist.org

16. Llacsa J, Martín J, Leyva F. 2007. Evaluación de indicadores biométricos en llamas (Lama glama) de las variedades ch'accu y k'ara. Rev Inv Vet, Perú 18: $1-10$.

17. MacDonagh EJ. 1949. Observaciones sobre guanacos cruzados con llamas. Rev Museo de la Plata Zoología 2(10): 5-84.

18. Maquera Llano FE. 1991. Caracterización y persistencia fenotípica en 1lamas Karas y Lanudas del Centro Experimental La Raya-Puno. Tesis de Magíster. Lima: Univ Nacional Agraria La Molina. $81 \mathrm{p}$.

19. Paca EP. 1977. Biometría de la llama en comunidades de Santa Rosa de Juli. Tesis de Médico Veterinario Zootecnista. Puno: Univ Nacional del Altiplano. 61 p.

20. Pumayalla A, Osorio S, Mestas C. 1985. Aspectos biométricos en llamas. En: VIII Reunión Científica Anual de la Asociación Peruana de Producción Animal. Huancayo: APPA. 
21. Sambrook J, Fritsch EF, Maniatis T. 1989. Molecular cloning. A laboratory manual. $2^{\text {nd }}$ ed. New York, USA: Cold Spring Harbor Laboratory Press. 1110 p.

22. Solís R. 2000. Producción de camélidos sudamericanos. Estudio zootécnico de la llama y del guanaco. $2^{\circ}$ ed. Cerro de Pasco, Perú: Imprenta Ríos. 230 p.

23. Stanley HF, Kadwell M, Wheeler JC. 1994. Molecular evolution of the family Camelidae: a mitochondrial DNA study. P Roy Soc Lond B Bio 256: 1-6.

24. Sumar J. 1993. Enfoque: ¿existen razas de llamas? Rev Inv Pec IVITA 6 (2): 87-93.

25. Wheeler JC. 1982. Aging llamas and alpacas by their teeth. Llama World 1(2): 12-17.

26. Wheeler JC. 1994. Cartas al director. Rev Inv Pec, IVITA 7(1): 67-69.

27. Wheeler JC. 1995. Evolution and present situation of the South-American
Camelidae. Biol J Linnean Soc 52: 271295.

28. Wheeler JC, Russel AJF, Redden $R$. 1995. Llamas and alpacas: pre-conquest breeds and post-conquest hybrids. J Archaeological Sci 22: 833-840.

29. Wheeler JC, Hoces D, Bruford M. 2006. Proyección estocástica de poblaciones del guanaco peruano. En: Actas IV Congreso Mundial sobre Camélidos. Catamarca, Argentina.

30. Zea O, Leyva V, García W, Falcón N. 2007. Evaluación de las medidas de grupa y muslo de la cría y ubre de la madre como indicadores fenotípicos en la selección temprana de llamas (Lama glama) para carne. Rev Inv Vet, Perú 18: 40-50.

31. Zúñiga M. 2004. Camélidos silvestres en la región Arequipa. ¿Dónde están y cuántos son? Arequipa, Perú: Asociación Nacional para el Desarrollo Sostenible, Andes Sostenibles. 115 p. 